\title{
Effect of hip and knee position on tensor fasciae latae elongation during stretching: An ultrasonic shear wave elastography study
}

\section{AUTHOR(S):}

Umehara, Jun; Ikezoe, Tome; Nishishita, Satoru; Nakamura, Masatoshi; Umegaki, Hiroki; Kobayashi, Takuya; Fujita, Kosuke; Ichihashi, Noriaki

\section{CITATION:}

Umehara, Jun ... [et al]. Effect of hip and knee position on tensor fasciae latae elongation during stretching: An ultrasonic shear wave elastography study. Clinical Biomechanics 2015, 30(10): 1056-1059

\section{ISSUE DATE:}

2015-12

URL:

http://hdl.handle.net/2433/231217

\section{RIGHT:}

(c) 2015. This manuscript version is made available under the CC-BY-NC-ND 4.0 license

http://creativecommons.org/licenses/by-nc-nd/4.0/; The full-text file will be made open to the public on 01 December 2016 in accordance with publisher's 'Terms and Conditions for Self-Archiving'.; この論文は出版社版でありません。引 用の際には出版社版をご硫認ご利用ください。; This is not the published version. Please cite only the published version. 
1 Effect of hip and knee position on tensor fasciae latae elongation during stretching: An

2 ultrasonic shear wave elastography study

3

4 Jun Umehara ${ }^{1)}$, Tome Ikezoe ${ }^{1)}$, Satoru Nishishita ${ }^{1)}$, Masatoshi Nakamura ${ }^{1,2)}$, Hiroki

$5 \quad$ Umegaki $^{1)}$, Takuya Kobayashi ${ }^{1)}$, Kosuke Fujita ${ }^{1)}$, Noriaki Ichihashi ${ }^{1)}$

$6 \quad{ }^{1)}$ Human Health Sciences, Graduate School of Medicine, Kyoto University, 53 Shogoin-

7 Kawahara-cho, Kyoto 606-8507, Japan

$8 \quad{ }^{2}$ Faculty of Health and Sports Science, Doshisha University, Kyoto, Japan

9

$10 *$ Corresponding author:

11 Jun Umehara $(\bowtie)$

12 Human Health Sciences, Graduate School of Medicine, Kyoto University

1353 Shogoin-Kawahara-cho, Sakyo-ku, Kyoto 606-8507, Japan

14 Telephone: +81-75-751-3935; Fax: +81-75-751-3909

$15 \quad$ E mail: umehara.jun.77z@st.kyoto-u.ac.jp

17 Word count, abstract: 223

18 Word count, main text: 2, 518

20 Abstract

21 Background: Decreased flexibility of the tensor fasciae latae is one factor that causes

22 iliotibial band syndrome. Stretching has been used to improve flexibility or tightness of

23 the muscle. However, no studies have investigated the effective stretching position for the

24 tensor fasciae latae using an index to quantify muscle elongation in vivo. The aim of this 
study was to investigate the effects of hip rotation and knee angle on tensor fasciae latae elongation during stretching in vivo using ultrasonic shear wave elastography.

Methods: Twenty healthy men participated in this study. The shear elastic modulus of the tensor fasciae latae was calculated using ultrasonic shear wave elastography. Stretching was performed at maximal hip adduction and maximal hip extension in 12 different positions with three hip rotation conditions (neutral, internal, and external rotations) and four knee angles $\left(0^{\circ}, 45^{\circ}, 90^{\circ}\right.$, and $\left.135^{\circ}\right)$.

Finding: Two-way analysis of variance showed a significant main effect for knee angle, but not for hip rotation. The post-hoc test for knee angle indicated that the shear elastic modulus at $90^{\circ}$ and $135^{\circ}$ were significantly greater than those at $0^{\circ}$ and $45^{\circ}$.

Interpretation: Our results suggest that adding hip rotation to the stretching position with hip adduction and extension may have less effect on tensor fasciae latae elongation, and that stretching at $>90^{\circ}$ of knee flexion may effectively elongate the tensor fasciae latae.

\section{Highlights}

- An effective stretching position for the tensor fasciae latae was examined.

- Shear wave elastography was used as an index to quantify muscle elongation

- Hip adduction, extension and $>90^{\circ}$ of knee flexion is the most effective position.

- Shear wave elastography is an effective method to investigate muscle elongation.

- High reliability was confirmed for the measurement of shear wave elastography.

Keywords

Ultrasonic shear wave elastography

Tensor fasciae latae 
$49 \quad$ Stretching 


\section{Introduction}

Iliotibial band (ITB) syndrome, one of the most common overuse injuries of the tensor fasciae latae (TFL) and ITB, often causes pain within the lateral portion of the knee joint. Competitive runners and cyclists (Ellis et al., 2007) as well as patients with knee osteoarthritis (Vasilevska et al., 2009) are reportedly at high risk of developing ITB syndrome. In a recent review of the mechanism of ITB syndrome, an abnormal increase in the compression forces between the ITB and the lateral epicondyle causes irritation and inflammation in the tissue beneath the ITB (Louw and Deary, 2014). Furthermore, two studies that investigated hip biomechanics using computer modeling reported that ITB hardness was influenced by the tension of the TFL (Birnbaum et al., 2004 and Fetto et al., 2002). Thus, it is important that the tightness and flexibility of the TFL are kept normal to avoid ITB hardness.

Static stretching is a common method for improving muscle flexibility (Nakamura et al., 2014). The stretching position and maneuver should be determined based on kinesiology and anatomy of the muscle. Because the function of the TFL is hip flexion, abduction, and internal rotation (Paré et al., 1981), stretching for TFL involves the joint motion opposite to the function of the muscle, i.e. hip extension, adduction, and external rotation. The two commonly used stretching positions for the TFL are; hip adduction, hip extension, and $90^{\circ}$ knee flexion (i.e., Ober test), and hip adduction, hip extension, and full knee extension (i.e., modified Ober test). The two commonly used stretching positions for the TFL are (1) hip adduction, hip extension, and $90^{\circ}$ knee flexion, which is consistent with the position used in the Ober test, and (2) hip adduction, hip extension, and full knee extension, which is consistent with the position used in the modified Ober test. The Ober test and modified Ober test are orthopedic examinations to check the 
shortening of the ITB length (Ober, 1936 and Kendall et al., 1970). However, no studies have quantitatively investigated the effective stretching position for the TFL in vivo because it was conventionally impossible to directly and noninvasively assess the quantified elongation of the hip muscles, which have multidirectional joint movements. The traditional method estimating muscle elongation such as range of motion or passive torque may be influenced by many factors such as other muscles, ligaments, and the joint capsule crossing the joint. Hence, elongation of individual muscles could not be assessed using these traditional measurements (Koo et al., 2014).

The recent development of a new ultrasound-based technique, namely ultrasonic shear wave elastography, allows the non-invasive and reliable measurement of muscle elasticity (Bercoff et al., 2004). Previous studies verified a strong linear relationship between passive muscle elongation measured using traditional methods and the shear elastic modulus measured by ultrasonic shear wave elastography in vitro (Eby et al., 2013 and Koo et al., 2013) or in vivo (Maïsetti et al., 2012 and Koo et al., 2014). Furthermore, some studies have investigated the effect of stretching on the muscle, using ultrasonic shear wave elastography (Taniguchi et al., 2015; Akagi and Takahashi, 2014 and Akagi and Takahashi, 2013). Therefore, ultrasonic shear wave elastography is a valid technology for investigating changes in muscle elongation in vivo.

A previous study investigating the effective stretching position reported that muscle elongation was influenced by the muscle moment arm (Umegaki et al., 2014) as well as the kinesiology and anatomy of the muscle. Additionally, the TFL has been reported to have the moment arms of hip internal rotation (Mansour and Pereira, 1987) and knee extension (Spoor and van Leeuwen, 1992). Therefore, we hypothesized that the TFL could be further stretched by adding hip external rotation and knee flexion to hip 
adduction and hip extension. The objective of this study was to investigate the effects of hip rotation and knee angle on the shear elastic modulus of the TFL during stretching using ultrasonic shear wave elastography in vivo.

\section{Methods}

\subsection{Subjects}

Twenty healthy men participated in this study [mean age, 23.3 (1.6) years; mean height, 172.9 (4.4) cm; mean weight, 66.6(6.2) kg]. Subjects were non-athletes and had not performed any excessive exercise. Subjects with a history of orthopedic or nervous system disease in their limbs were excluded. All subjects provided written informed consent. This study protocol was approved by the ethics committee of Kyoto University Graduate School and the Faculty of Medicine (E-1162).

We calculated the sample size needed for two-way analysis of variance (ANOVA) with repeated measures (effect size $=0.25, \alpha$ error $=0.05$, power $=0.8$ ) using $\mathrm{G}^{*}$ power 3.1 software (Heinrich Heine University, Duesseldorf, Germany). The results showed that 18 subjects were required; therefore, 20 subjects were recruited in this study to account for potential withdrawal.

\subsection{Experimental protocol}

All procedures were performed by the same two investigators: one performed the stretching maneuver, while the other measured the shear elastic modulus to ensure reproducibility.

Each subject lay in a supine position on a bed with the trunk securely fixed by a non-elastic band. The right lower limb was chosen for the measurement. The lower limb 
of the non-measurement side (the left side) was held at $125^{\circ}$ of hip flexion and maximal knee flexion to maintain posterior pelvic tilting. The rest position (REST) was defined as that with the hip in a neutral position (i.e., $0^{\circ}$ hip extension, $0^{\circ}$ abduction, and neutral rotation) and the knee in full extension. For all of the stretching positions, the hip was kept in maximal adduction and maximal extension. Stretching was measured in the combinations of three hip rotation conditions (neutral rotation, maximal internal rotation, and maximal external rotation) and four knee angles $\left(0^{\circ}, 45^{\circ}, 90^{\circ}\right.$, and $\left.135^{\circ}\right)$ for a total of 12 different conditions (Figure 1).

Regarding the joint movement order during the stretching maneuver, the knee was flexed first, followed by maximal hip adduction, hip extension, and hip rotation. During the stretching maneuver, the hip joints were moved to the maximal angle at which the subjects felt no discomfort or pain. The knee angles were fixed during the stretching maneuver using a Donjoy knee brace (DJO Global Inc., Vista, CA), which is a knee brace with a dial lock to maintain each angle during the stretching maneuver for rehabilitation. Each stretch was performed in a random order to preclude the effect of the measurement sequence. Since a previous study reported that $>2$ minutes of stretching decreased muscle stiffness (Nakamura et al., 2013), each stretch was performed for $<15$ seconds to prevent effects of changes in muscle stiffness on the TFL.

\subsection{Assessment of the shear elastic modulus}

143 The shear elastic modulus of the right TFL was measured at REST and in each of the 12

144 stretching positions using ultrasonic shear wave elastography (Axiporer; SuperSonic

145 Imagine, Axi-en-Provece, France) with an ultrasound transducer (50-mm-long SL-15-4

146 linear ultrasound transducer). The measurement site was defined as the midpoint between 
147 the anterior superior iliac spine and the greater trochanter of the femur. The region of

148 interest (ROI) was set up near the central point of the muscle belly in the image. A10-

149 mm-diameter circle was drawn around the center of the ROI. The mean shear wave

150 propagation speed (m/s) within the circle was automatically calculated. The shear elastic

151 modulus (G) was converted from the shear wave propagation speed (V) using the

152 following equation:

$153 \mathrm{G}=\rho \mathrm{V}^{2}$

154 where $\rho$ is the muscle mass density, which is presumed to be $1,000 \mathrm{~kg} / \mathrm{m}^{3}$ (Gennisson et 155 al., 2005; Nordez et al., 2008 and Nakamura et al., 2014).The shear elastic modulus was 156 measured twice and the mean value was used for the analysis. Previous studies reported that the shear elastic modulus calculated by shear wave elastography was strongly correlated with the degree of muscle elongation (Eby et al., 2013 and Koo et al., 2013).

\subsection{Measurement reliability}

161 Reliability of the shear elastic modulus measurements was ascertained using the intraclass correlation $(1,1)\left(\mathrm{ICC}_{1,1}\right)$. ICC 1,1 was calculated by the shear elastic modulus of the two measurements at each of the REST and stretching positions.

\subsection{Statistical analysis}

166 Statistical analysis was performed using SPSS (version 18.0; SPSS Japan Inc., Tokyo, Japan). To determine whether TFL was elongated in each stretching position, differences in shear elastic modulus between the REST and each stretching position were assessed using the paired student's t-test with Bonferroni revision. Two-way ANOVA with 
positions]) was used to determine the effects of hip rotation and knee angle on the shear elastic modulus. When a significant main effect was found, the post-hoc test was performed. A confidence level of 0.05 was used in all of the statistical tests. For the shear elastic modulus in the stretching position, the effect size was calculated from the formula: $\left(\mathrm{X}_{1}-\mathrm{X}_{2}\right) / \sqrt{ }\left[\left(\mathrm{S}_{1}{ }^{2}+\mathrm{S}_{2}{ }^{2}\right) / 2\right]$ using $\mathrm{G}^{*}$ power 3.1 software (Heinrich Heine University,

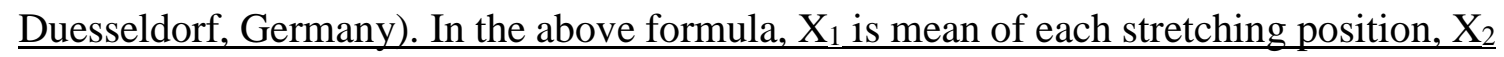

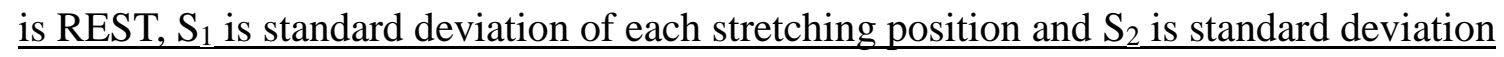
of REST.

\section{Results}

\subsection{Measurement reliability}

The reliability of the shear elastic modulus for the REST and stretching positions is shown in Table 1 . The ICC 1,1 was $0.932-0.986$ for all positions, which was significant.

3.2 Effect of hip and knee position on stretching - induced tensor fasciae latae elongation The shear elastic modulus of each stretching position is shown in Table 2 as mean (standard deviation), with the effect size. The shear elastic modulus at REST was 13.4 (5.2) $\mathrm{kPa}$. When the shear elastic modulus was compared between the REST and stretching positions, the shear elastic modulus of each stretching position was significantly higher than that of the REST position $(p<0.05)$. Two-way ANOVA showed a significant main effect of the knee angle $(F=15.35, p<0.01)$ but not hip rotation $(F=$ 1.13, $p=0.33$, with no significant interaction between hip rotation and knee angle $(F=$ $0.87, p=0.52$ ). The post-hoc test for knee angle indicated that the shear elastic modulus at $90^{\circ}$ and $135^{\circ}$ were significantly higher than those at $0^{\circ}$ and $45^{\circ}$. However, there were 
no significant differences between $0^{\circ}$ and $45^{\circ}$ or between $90^{\circ}$ and $135^{\circ}$ (Figure 2).

196

197

\section{Discussion}

\subsection{Measurement reliability}

199 In this study, the ICC $_{1,1}$ of the measurement was $0.932-0.986$ for all positions, which was significant. An ICC value of 0.40 is generally considered poor reliability, $0.40-0.75$ is moderate to good, and 0.75 is excellent (Leong et al., 2013). We consider the data in this reliability study valid because the $\mathrm{ICC}_{1,1}$ observed here was similar to that in a previous study (Leong et al., 2013).

4.2 Effect of hip and knee position on stretching - induced tensor fasciae latae elongation This is the first study to examine the effective stretching position of TFL using the shear elastic modulus measured by ultrasonic shear wave elastography, which was defined as the degree of muscle elongation in vivo. The main findings of this study were that the stretching positions with hip adduction and extension may effectively elongate TFL, which could more effectively be stretched by the addition of $>90^{\circ}$ of knee flexion at this stretching position than by the addition of hip rotation.

We hypothesized that the TFL could be further stretched by adding hip external rotation and knee flexion to hip adduction and hip extension. However, our hypothesis was only partially proven because one part of the hypothesis stating that the TFL could be further stretched by adding hip external rotation was disproved and the another part stating that the TFL could be further stretched by adding knee flexion was confirmed. The moment arm can be calculated by dividing the amount of elongation of the muscle tendon unit (MTU) by the changes in joint angle (tendon excursion methods) (Maganaris et al., 
2000). Therefore, the greater the moment arm and changes in joint angles are, the more elongated the MTU is (Umegaki et al., 2014). As for the moment arm of the TFL, the moment arms of hip abduction and hip flexion are large (Dostal et al., 1986), whereas the moment arm of hip internal rotation is small (Mansour and Pereira, 1987) or nonexistent (Dostal et al., 1986). Thus, due to moment arm of hip rotation, no effects of hip rotation on the TFL might have been observed in our study. On the other hand, our results indicated that the shear elastic modulus of the TFL was influenced by knee angle and that a stretching position with $>90^{\circ}$ of knee flexion may effectively elongate the TFL. The TFL has a moment arm on knee extension through the range of the knee joint motion (Spoor and van Leeuwen, 1992), a finding that is consistent with our result that indicated greater elongation of the TFL as the knee is flexed. indicated that the stretching position with $90^{\circ}$ of knee flexion (i.e., Ober test) was more effective for stretching the TFL than that with a $0^{\circ}$ knee angle ( i.e., modified Ober test). However, Wang et al. (2006) reported that the stretching position with a $0^{\circ}$ knee angle (i.e., modified Ober test) was more effective than that with $90^{\circ}$ of knee flexion (i.e., Ober test), which is inconsistent with our result. This previous study (Wang et al., 2006) compared the properties of ITB at the stretching position between knee flexion and knee extension using an ultrasonographic image and concluded that the modified Ober test was more effective for stretching the TFL. In our study, the muscle belly of the TFL was compared to determine the effective stretching position, which might have caused this inconsistency. Furthermore, this inconsistency suggests that there might be a difference in tension applied between the TFL and ITB with knee angle changes during stretching.

242 It is possible that the inconsistency is caused by the complicated structures of the ITB and 
surrounding tissues. The ITB has many attachments other than the TFL, including the gluteus maximus (Vieira et al., 2007), vastus lateralis, biceps femoris, lateral patellar retinaculum, patella, and patellar tendon (Baker et al., 2011). Therefore, further research is required to determine the difference in the stretching position between the TFL and ITB, with a focus on the hip and knee positions.

Our findings showing the effective stretching position of the TFL may be useful in the clinical and sports settings. However, this study had some limitations. First, the subjects in this study were healthy young men without a history of orthopedic or nervous system disease. Therefore, similar effects cannot always be expected in elderly people or patients with a limited range of motion. Second, we investigated only the acute effects of stretching position; therefore, it is unclear whether a long-term intervention program affects TFL elongation. Further research is required to determine the intervention effect in elderly people and patients with a limited range of motion.

\section{Conclusion}

258 Here we investigated the effects of hip rotation and knee flexion during stretching on muscle elongation of the TFL using the shear elastic modulus measured by ultrasonic shear wave elastography. Our findings suggest that adding $>90^{\circ}$ of knee flexion to the stretching position with hip adduction and extension may effectively elongate the TFL.

263 Acknowledgements

264 The authors wish to thank Dr. Satoshi Hasegawa, Assistant Professor of Graduate School of Medicine, Kyoto University for advice on experimental design. This work was supported by the Grant-in-Aid for Scientific Research (B) $15 \mathrm{H} 03043$. 


\section{References}

Akagi, R., Takahashi, H., 2013. Acute effect of static stretching on hardness of the gastrocnemius muscle. Med. Sci. Sports Exerc. 45, 1348-1354. doi:10.1249/MSS.0b013e3182850e17

Akagi, R., Takahashi, H., 2014. Effect of a 5-week static stretching program on hardness of the gastrocnemius muscle. Scand. J. Med. Sci. Sports 24, 950-957. doi:10.1111/sms.12111

Baker, R.L., Souza, R.B., Fredericson, M., 2011. Iliotibial band syndrome: soft tissue and biomechanical factors in evaluation and treatment. PM R 3, 550-61. doi:10.1016/j.pmrj.2011.01.002

Bercoff, J., Tanter, M., Fink, M., 2004. Supersonic shear imaging: A new technique for soft tissue elasticity mapping. IEEE Trans. Ultrason. Ferroelectr. Freq. Control 51, 396-409. doi:10.1109/TUFFC.2004.1295425

Birnbaum, K., Siebert, C.H., Pandorf, T., Schopphoff, E., Prescher, a., Niethard, F.U., 2004. Anatomical and biomechanical investigations of the iliotibial tract. Surg. Radiol. Anat. 26, 433-446. doi:10.1007/s00276-004-0265-8

Dostal, W.F., Soderberg, G.L., Andrews, J.G., 1986. Actions of hip muscles. Phys. Ther. 66, 351-361. doi:10.1097/01241398-198703000-00046

Eby, S.F., Song, P., Chen, S., Chen, Q., Greenleaf, J.F., An, K.-N., 2013. Validation of shear wave elastography in skeletal muscle. J. Biomech. 46, 2381-7. doi:10.1016/j.jbiomech.2013.07.033

Ellis, R., Hing, W., Reid, D., 2007. Iliotibial band friction syndrome--a systematic review. Man. Ther. 12, 200-8. doi:10.1016/j.math.2006.08.004

Fetto, J., Leali, A., Moroz, A., 2002. Evolution of the Koch model of the biomechanics of the hip: Clinical perspective. J. Orthop. Sci. 7, 724-730. doi:10.1007/s007760200130 
294

295

296

297

298

299

300

301

302

303

304

305

306

307

308

309

310

311

312

313

314

315

316

317

318

319

320

321

322

Gajdosik, R.L., Sandler, M.M., Marr, H.L., 2003. Influence of knee positions and gender on the Ober test for length of the iliotibial band. Clin. Biomech. 18, 77-79. doi:10.1016/S0268-0033(02)00168-7

Gennisson, J.L., Cornu, C., Catheline, S., Fink, M., Portero, P., 2005. Human muscle hardness assessment during incremental isometric contraction using transient elastography. J. Biomech. 38, 1543-50. doi:10.1016/j.jbiomech.2004.07.013

Koo, T.K., Guo, J.-Y., Cohen, J.H., Parker, K.J., 2013. Relationship between shear elastic modulus and passive muscle force: an ex-vivo study. J. Biomech. 46, 20539. doi:10.1016/j.jbiomech.2013.05.016

Koo, T.K., Guo, J.-Y., Cohen, J.H., Parker, K.J., 2014. Quantifying the passive stretching response of human tibialis anterior muscle using shear wave elastography. Clin. Biomech. (Bristol, Avon) 29, 33-9. doi:10.1016/j.clinbiomech.2013.11.009

Leong, H.-T., Ng, G.Y.-F., Leung, V.Y.-F., Fu, S.N., 2013. Quantitative estimation of muscle shear elastic modulus of the upper trapezius with supersonic shear imaging during arm positioning. PLoS One 8, e67199. doi:10.1371/journal.pone.0067199

Louw, M., Deary, C., 2014. The biomechanical variables involved in the aetiology of iliotibial band syndrome in distance runners - A systematic review of the literature. Phys. Ther. Sport 15, 64-75. doi:10.1016/j.ptsp.2013.07.002

Maganaris, C.N., Baltzopoulos, V., Sargeant, A.J., 2000. In vivo measurement-based estimations of the human Achilles tendon moment arm. Eur. J. Appl. Physiol. 83, 363-9.

Maïsetti, O., Hug, F., Bouillard, K., Nordez, A., 2012. Characterization of passive elastic properties of the human medial gastrocnemius muscle belly using supersonic shear imaging. J. Biomech. 45, 978-84. doi:10.1016/j.jbiomech.2012.01.009

Mansour, J.M., Pereira, J.M., 1987. Quantitative functional anatomy of the lower limb with application to human gait. J. Biomech. 20, 51-58. doi:Doi: 10.1016/00219290(87)90266-1 
Nakamura, M., Ikezoe, T., Kobayashi, T., Umegaki, H., Takeno, Y., Nishishita, S., Ichihashi, N., 2014. Acute effects of static stretching on muscle hardness of the medial gastrocnemius muscle belly in humans: An ultrasonic shear-wave elastography study. Ultrasound Med. Biol. 40, 1991-1997. doi:10.1016/j.ultrasmedbio.2014.03.024

Nakamura, M., Ikezoe, T., Takeno, Y., Ichihashi, N., 2013. Time course of changes in passive properties of the gastrocnemius muscle-tendon unit during 5 min of static stretching. Man. Ther. 18, 211-5. doi:10.1016/j.math.2012.09.010

Nordez, a, Gennisson, J.L., Casari, P., Catheline, S., Cornu, C., 2008. Characterization of muscle belly elastic properties during passive stretching using transient elastography. J. Biomech. 41, 2305-11. doi:10.1016/j.jbiomech.2008.03.033

Ober, F.R., 1936. The role of the iliotibial band and fascia lata as a factor in the causation of low-back disabilities and sciatica. J. Bone Joint Surg. Am. 18, 105110.

Paré, E.B., Stern, J.T., Schwartz, J.M., 1981. Functional differentiation within the tensor fasciae latae. A telemetered electromyographic analysis of its locomotor roles. J. Bone Joint Surg. Am. 63, 1457-71.

Spoor, C.W., van Leeuwen, J.L., 1992. Knee muscle moment arms from MRI and from tendon travel. J. Biomech. 25, 201-6.

Taniguchi, K., Shinohara, M., Nozaki, S., Katayose, M., 2015. Acute decrease in the stiffness of resting muscle belly due to static stretching. Scand. J. Med. Sci. Sports 25, 32-40. doi:10.1111/sms.12146

Umegaki, H., Ikezoe, T., Nakamura, M., Nishishita, S., Kobayashi, T., Fujita, K., Tanaka, H., Ichihashi, N., 2014. The effect of hip rotation on shear elastic modulus of the medial and lateral hamstrings during stretching. Man. Ther. 7-10. doi:10.1016/j.math.2014.07.016

Vasilevska, V., Szeimies, U., Stäbler, A., 2009. Magnetic resonance imaging signs of iliotibial band friction in patients with isolated medial compartment osteoarthritis of the knee. Skeletal Radiol. 38, 871-5. doi:10.1007/s00256-009-0704-z 
352 Vieira, E.L.C., Vieira, E.A., da Silva, R.T., Berlfein, P.A.D.S., Abdalla, R.J., Cohen, M., 2007. An anatomic study of the iliotibial tract. Arthroscopy 23, 269-74. doi:10.1016/j.arthro.2006.11.019

Wang, T.-G., Jan, M.-H., Lin, K.-H., Wang, H.-K., 2006. Assessment of stretching of the iliotibial tract with Ober and modified Ober tests: an ultrasonographic study. Arch. Phys. Med. Rehabil. 87, 1407-11. doi:10.1016/j.apmr.2006.06.007 
$359 \quad$ Figure captions

360 Figure 1. Representative image of the stretching position. The subject is seen stretching 361 to maximum hip adduction, extension, neutral rotation, and $45^{\circ}$ of knee flexion in the 362 supine position.

363

364 Figure 2. Comparison of the shear elastic modulus $(\mathrm{kPa})$ in the post-hoc test for knee 365 angle. Although no significant differences are noted between $0^{\circ}$ and $45^{\circ}(p=0.13)$ and 366 between $90^{\circ}$ and $135^{\circ}(p=1.00)$, the shear elastic modulus are significantly higher at $90^{\circ}$ 367 and $135^{\circ}$ than at $0^{\circ}(p<0.01)$ and $45^{\circ}(p=0.05)$.

$368 * p<0.05, * * p<0.01$, significant difference among knee angles. 369 


\begin{tabular}{|c|c|c|}
\hline Stretching position & ICC & $95 \% \mathrm{CI}$ \\
\hline REST & 0.980 & $0.950-0.992$ \\
\hline Hip N, Knee $0^{\circ}$ & 0.934 & $0.844-0.973$ \\
\hline Hip N, Knee $45^{\circ}$ & 0.965 & 0.916-0.986 \\
\hline Hip N, Knee $90^{\circ}$ & 0.962 & 0.909-0.985 \\
\hline Hip N, Knee $135^{\circ}$ & 0.975 & $0.938-0.990$ \\
\hline Hip IR, Knee $0^{\circ}$ & 0.986 & 0.967-0.995 \\
\hline Hip IR, Knee $45^{\circ}$ & 0.968 & 0.923-0.987 \\
\hline Hip IR, Knee $90^{\circ}$ & 0.934 & $0.844-0.973$ \\
\hline Hip IR, Knee $135^{\circ}$ & 0.950 & $0.880-0.980$ \\
\hline Hip ER, Knee $0^{\circ}$ & 0.980 & 0.950-0.992 \\
\hline Hip ER, Knee $45^{\circ}$ & 0.948 & 0.875-0.979 \\
\hline Hip ER, Knee $90^{\circ}$ & 0.963 & 0.911-0.985 \\
\hline Hip ER, Knee $135^{\circ}$ & 0.932 & 0.840-0.972 \\
\hline
\end{tabular}

370 Table 1. Reliability of shear elastic modulus measurements.

371 ICC, intraclass correlation coefficient $(1,1)$; 95\% CI, 95\% confidence interval;

$372 \mathrm{~N}$, neutral rotation; IR, internal rotation; ER, external rotation 


\begin{tabular}{|c|c|c|c|c|}
\hline & & \multicolumn{3}{|c|}{ Hip } \\
\hline & & $\begin{array}{l}\text { Neutral } \\
\text { rotation }\end{array}$ & $\begin{array}{l}\text { Internal } \\
\text { rotation }\end{array}$ & $\begin{array}{l}\text { External } \\
\text { rotation }\end{array}$ \\
\hline \multirow{4}{*}{ Knee } & $0^{\circ}$ & $\begin{array}{c}24.6(8.0), \\
\text { effect size: } 1.7\end{array}$ & $\begin{array}{c}26.8 \text { (15.7), } \\
\text { effect size: } \underline{1.1}\end{array}$ & $\begin{array}{c}23.4 \text { (9.2), } \\
\text { effect size: } \underline{1.3} \\
\end{array}$ \\
\hline & $45^{\circ}$ & $\begin{array}{c}30.2 \text { (10.5), } \\
\text { effect size: } \underline{2.0}\end{array}$ & $\begin{array}{c}29.0 \text { (11.1), } \\
\text { effect size: } \underline{1.8}\end{array}$ & $\begin{array}{c}29.2 \text { (11.1), } \\
\text { effect size: } \underline{1.8} \\
\end{array}$ \\
\hline & $90^{\circ}$ & $\begin{array}{c}38.1 \text { (11.0), } \\
\text { effect size: } \underline{2.9}\end{array}$ & $\begin{array}{c}38.1 \text { (14.5), } \\
\text { effect size: } \underline{2.3}\end{array}$ & $\begin{array}{c}35.2 \text { (12.1), } \\
\text { effect size: } \underline{2.3} \\
\end{array}$ \\
\hline & $135^{\circ}$ & $\begin{array}{c}38.4 \text { (17.5), } \\
\text { effect size: } \underline{1.9}\end{array}$ & $\begin{array}{c}32.7 \text { (12.9), } \\
\text { effect size: } \underline{2.0}\end{array}$ & $\begin{array}{c}35.2 \text { (12.3), } \\
\text { effect size: } 2.3\end{array}$ \\
\hline
\end{tabular}

374 Table 2. Shear elastic modulus $(\mathrm{kPa})$ of the tensor fasciae latae in the stretching position.

375 Two-way analysis of variance showed a significant main effect of the knee angle but not

376 hip rotation. Values are expressed as mean (standard deviation). 
$378 \quad$ Figure1

379

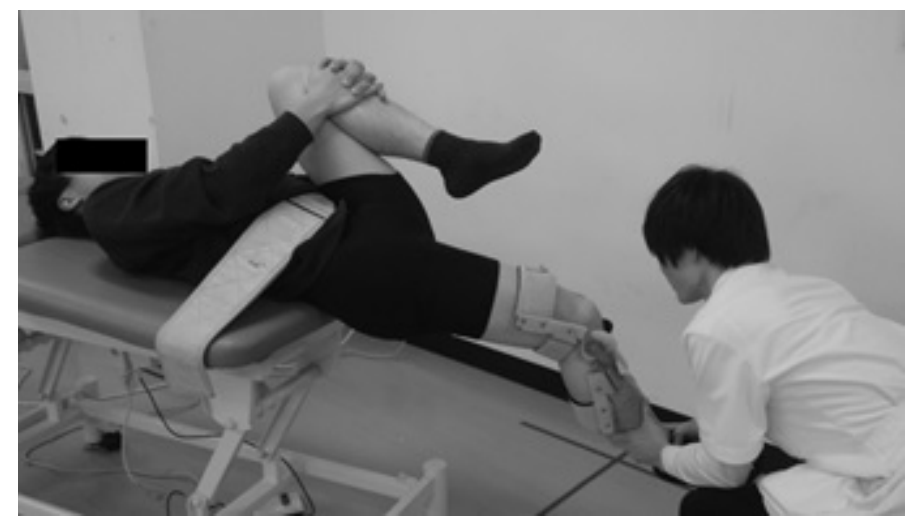

380

381 
382 Figure 2

383

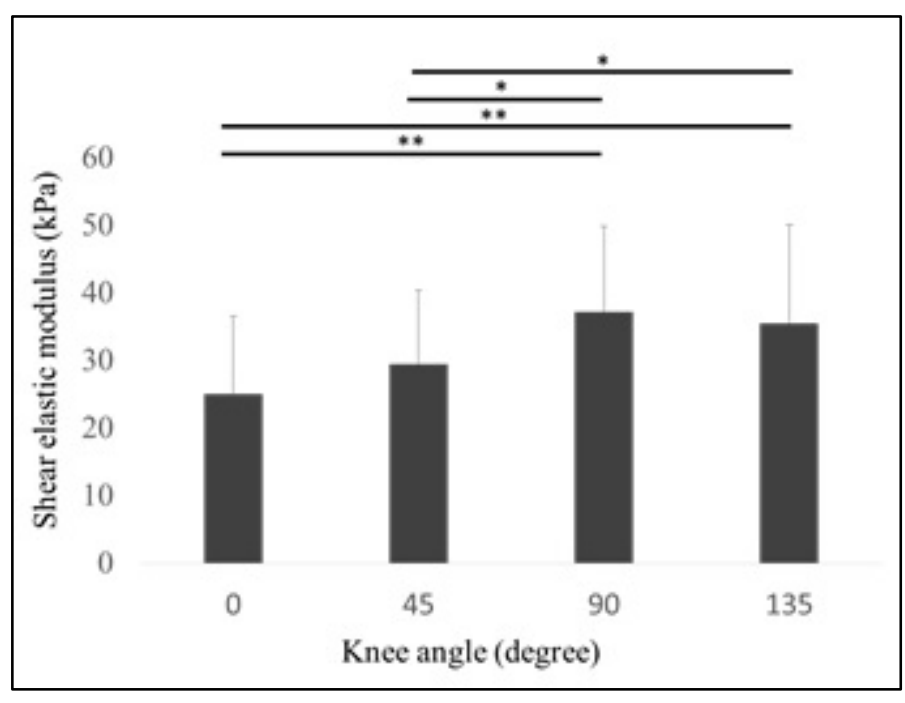

